\title{
Comparison and Contrast of the Translations of Gone With the Wind Based on Norms
}

\author{
Xunfeng Yin \\ TaiShan University, Tai'an, Shandong, 271000, China
}

\begin{abstract}
In this article, by using Gideon Toury's theory of translation studies and focusing on norm, the author intends to analyze two commonly accepted editions, Fu's version and Huang's version of Gone with the Wind. Consequently, it is proved that controlled by a specific translation norm, translators tend to take a specific translation strategy, so when evaluating all translated texts, the translation norms at that time should also be taken into consideration besides some set standards.
\end{abstract}

Index Terms — descriptive translation studies, translation norm, Gone with the Wind

\section{Dispute of Chinese Editions of GONE WITH THE WiND}

Every classical English literary work will be translated into different translations by different translators at different times. Therefore, if people, especially college students, want to read the translated versions of English literary classics, they may be confused about which translation or which is better.

Gone with the Wind, written by Margaret Mitchell, an American writer, was published in 1936, which is a case in point. In China, the film, adapted from the novel, was released in Shanghai in 1940 and was hailed by Shanghainese during more than forty days of screening. A few months later, the first edition of the novel, translated by Fu Donghua, was published in Chinese and republished in 1979 (Fu, 1979). Decades after it was introduced into China, Fu's version dominated its translation. From the 1990s, many translators began to retranslate the novel. So far, it is estimated that there are at least eight versions.

Inevitably, articles about Gone with the Wind emerge one after another on translation issues.

For example, there are three articles using skopostheorie of German functionalism to evaluate two versions. Among them, Wen Jun (2003) took the versions of Fu Donghua and Huang Huairen as an example in his essay A Functionalist Critique of Two Chinese Translations of Gone with the Wind, saying that the essence of translation mainly depends on the purpose or task of translation, so Fu adopted domestication and Huang used foreignization, therefore their translations have different own advantages and disadvantages. However, Wen Jun neglected that the functional approach is mainly applicable to practical writing, and the translation of Gone with the Wind is more inclined to literary translation.

"Translation is not only a kind of language transfer, but also a kind of cross-cultural communication. We should pay full attention to the macro-cultural factors involved in the process of translation," Feng Qinghua (1998) said in his Studying Translation from the Macroscopical Viewpoint of Cultural Communication. So he used historical and descriptive methods to analyze Fu's translation and Daikan's translation. He said that the specific socio-cultural environment and vernacular language at that time influenced and restricted his translation, but his translation was recognized by the readers at that time, so his version belonged to the past, and we should respect his translation. Although the new objective conditions now require a new version of the novel to adapt to a changing socio-cultural environment, there is no absolute domestication and foreignization in terms of the translated version. In fact, according to the descriptive translation studies, Feng's "specific sociocultural environment and vernacular Chinese at that time", "new objective conditions" and "changing sociocultural environment" can be regarded as translation norms for a period of time. Of course, his point of view tells us how to evaluate translation from a historical perspective, not absolute static. Why do different translators in different periods translate the same work in different ways, and why are different versions treated differently in different periods? With Gideon Toury's translation norms, the problem will be better explained and the mystery of choosing which version will be clearer.

\section{ANALYSIS OF DifFERENT EDITIONS By USING TRANSLATION NORMS}

Israeli scholar Gideon Toury is concerned about what translation is achieved in certain cultures, what are the functions of these translations, and what kind of prescription culture will contribute to translation studies. He focuses on translation, especially literary translation, will have a certain impact on the development of specific cultures, and he emphasizes on the position of translation in a particular culture and its influence on translation strategies and the whole translation process. 
According to Toury's norm, we know that in different times, the norms of translation are different, translation then will become a relative concept. The same is true of the translation. We should not use the same criteria to evaluate all the translated texts, and we should also take into account the translation norms at that time.

This paper selects the versions of $\mathrm{Fu}$ Donghua and Huang Huairen (the first sixteen chapters) and makes a comparison and contrast from the perspective of translation norms. Mr. Huang's version can also be considered a representative of foreignization among other versions of the same period, although the Fu's version is regarded as a masterpiece of domestication. The following section will undoubtedly prove this argument.

\section{A. The Translation of Characters and Places' Name}

This, of course, is the first and the most obvious point of difference. Obviously, in Fu's translation characters seemed to be Chinese, they all had their family names, the first names exactly in Chinese way. And the places in the novel also were translated just like the city in China, so when Chinese readers read this novel, they would think the story takes place somewhere in China, they would find it familiar and easy to understand. While in Huang's translation, he strictly translated them according to their pronunciation, which definitely is in accordance with his assertion "Fu's translation has no connection with the geographic characteristics of that area, his way of translating names should be corrected now". (Huang, 1991, p.3)

\section{B. The Translation of Literary Quotations}

Since it is the translation of a foreign novel, then there certainly would have literary quotations, something that only belongs to its own country. Towards this point, the two translators adopted different ways, that is, for most of them, Fu simply did not translate or used other similar Chinese proverbs to replace them, but Huang translated most of them directly without changing the original meanings. Here are some examples:

(1) As always since childhood, this was, for Scarlett, a moment for adoration of Ellen, rather than the Virgin. Sacrilegious though it might be, Scarlett always saw, through her closed eyes, the upturned face of Ellen and not the Blessed Virgin, as the ancient phrases were repeated, "Health of the Sick," "Seat of Wisdom," "Refuge of Sinners," "Mystical Rose" - they were beautiful words because they were the attributes of Ellen. (Mitchell, 2002, p61)

(2) She had often heard of people cutting off their noses to spite their faces but heretofore it had been only a figure of speech. Now she knew just what it meant. (Mitchell, 2002, p114)

(3) They might be dying in thousands but, like the fruit of the dragon's teeth, thousands of fresh men in grey and butternut with the Rebel yell on their lips would spring up from the earth to tae their places. (Mitchell, 2002, p220)

In the above three examples, towards literary quotations, they adopted different ways. For the first one, Mystical Rose, Fu just translated it as 神秘的蓄薇 with no other explanation, for the proverb cutting off their noses to spite their faces, Fu just used a Chinese proverb 吞了毒药去药老虎 to replace it, and for like the fruit of the dragon's teeth, Fu did not translate. As for Huang, he used the same way to treat literary quotations, namely, made the direct translation of the lines with notes, for the first one, he added the note “基督教认为玫瑰是“尽善尽美”的象征, 常用以赞颂圣母玛利 亚, 称之为“神秘的玫瑰”, , and for the second one, he added the note “西浐, 喻害己以害人”, and for the last one he added that “按日尔曼神话，腓尼基王子种下龙赤，化为武士，互相砍杀.”

Again what Fu did was to make the story easy to be accepted by Chinese readers, and what Huang did was to "keep the foreign color", "try as much as possible to keep the original works' figure of speech without borrowing proverbs and phrases from Chinese". (Huang, 1991, p.4)

\section{The Difference of Language}

The two translators translated the novel at different times, one in 1930s and the other in 1980s, so the question of language reality must be raised. In 1930s, vernacular Chinese was gradually accepted after the May 4th Movement of 1919, but it had not been fully developed, and could not be fully, freely and properly used. Besides, the literary Chinese that prevailed in feudal society could not extinct, still had a certain impact. Consequently, Fu's language in the translation was half the vernacular Chinese and half classical Chinese. Then about fifty years later, when Chinese language was fully developed, Huang retranslated the novel in modern language, so there would be not the same language style they use.

(4) “Young misses whut frowns an' pushes out dey chins an' says, 'Ah will' an' 'Ah woan' mos' gener' ly doan ketch husbands," prophesied Mammy gloomily, "Young misses should cas' down dey eyes an' say, 'Well, suh, Ah mout' an' Jes' as you say, suh."” (Mitchell, 2002, p51)

(5) Then, after a discreet pause which gave Gerald's splutterings time to die away, she knocked on the door and handed the dress to her mother. (Mitchell, 2002, p62)

(6) Although born to the ease of plantation life, waited on hand and foot since infancy, the faces of the three on the porch were neither slack nor soft. They had the vigour and alertness of country people who have spend all their lives in the open and troubled their heads very little with dull things in books. (Mitchell, 2002, p2)

Fu translated “Ah (actually it is “I')”, “well, sir” into“俺”, “是啦, 您那”, and turned “splutterings time to die away”, “the three”, “born to the ease of plantation life” into “让父亲的唾沫星子干一干”, “两位哥儿和一位小姐”, “打出娘胎就有人从头到脚的服侍着”. And comparatively, Huang translated these words differently, as “我”, “是 
的, 先生”, “待杰拉尔德气急败坏的话音逐渐消逝”, “这三个男女青年”, “出生于庄园主家庭, 从小就有人侍候长 大”. From the language they use, we could easily confirm their language characteristics that I mentioned above, Fu's is mixed with classical Chinese and vernacular Chinese, is freely humorously used. When we read his translation, we would figure out this is a novel written several decades ago. In contrast, Huang's is rather like what people say now, but a little formal.

\section{The Translation of Long Sentences}

In English novels or articles, sentences tend to be rather long. Towards the long sentences, Fu generally broke the sentence structure, reconstructed the logic order, and translated them into short Chinese sentences. On the contrary, most of the time Huang just followed the sentence structure of the original text without changing its logic order, and finally it turned out to be long Chinese sentence in the process of translation. In fact, not only for long sentences, their translation strategies for the comparatively short sentences are basically the same. Moreover, in English, the modifiers of a central word also tend to be rather long. At this point, Fu just rearranged the modifiers, making some of them construct another sentence, but in Huang's translation, things would be different, he usually followed the sequence of the modifiers and made them all stay where they were.

(7) True, he never made love to her, nor did the clear gray eyes ever glow with that hot light Scarlett knew so well in other men. (Mitchell, 2002, p21)

(8) If I can just see him privately before supper, perhaps I'll find out the truth - that it's just one of the twins' nasty practical jokes. (Mitchell, 2002, p20)

(9) He did not know that he had taken nearly ten years to arrive, for it never occurred to him that his neighbors had eyed him askance at first. (Mitchell, 2002, p43)

Towards "nor did the clear gray eyes ever glow with that hot light Scarlett knew so well in other men (Mitchell, 2002, p21)" Fu broke it into two parts, translating "Scarlett knew so well in other men", the modifier of "hot light", later, the Chinese translation became "他的眼睛也从不曾流露过那种热烈的光，像思嘉在旁的男人身上看见的”; Huang made the modifier "Scarlett knew so well in other men" still modify the central words "hot light", the Chinese translation was still a long sentence “他那澄澈的灰色眼睛也从来没有流露出斯卡利特在别的男人眼里常见到的热 切的光辉”.

For "perhaps I'll find out the truth — that it's just one of the twins' nasty practical jokes (Mitchell, 2002, p20)", Fu made a judgment of the relationship between "perhaps I'll find out the truth" and "that it's just one of the twins' nasty practical jokes (Mitchell, 2002, p20)”, used “因而” replaced the dash, then the translated sentence became “或许可以 探出事情的真相，因而证明他哥俩方才的话不过是跟她开开玩笑的”. Huang followed the sentence structure without changing the dash, and made the translation as “说不定就可以弄明白真相一即不过是两兄弟的又一次恶作 剧罢了”.

And as for "He did not know that he had taken nearly ten years to arrive, for it never occurred to him that his neighbors had eyed him askance at first (Mitchell, 2002, p43)", Fu broke this sentence into two Chinese sentences, reversed the sequence of the first part of the sentence, and split the other part of the original sentence into three parts, finally the translated sentence became “他这做本地人的一步工作, 是差不多做了十年才完工的, 但自己却并不知 道。因为他初来的时候, 那些邻舍家都对他侧目而视, 这情形是他始终不曾想起过的”. And Huang still obeyed the original sentence structure and did not make any changes, and at last the Chinese sentence was “他并不知道他几乎 花了十年时间方才得到当地人的认可, 因为他始终没有觉察到他的邻居们最初对他是侧目而视的”.

In conclusion, Fu broke the long sentences, withdrew the modifier, and made them into short Chinese sentences, while Huang kept all the modifiers, especially attributes, modified the key word without any pause, therefore it turned out that Huang's translation followed the structure of the original sentence and was rather long sentence.

\section{E. Full Translation or Partial Translation}

Many sentences that Fu translated are not full translation, they are changed in different aspects: the most obvious one is deletion, from the deletion of several words to the deletion of paragraphs; then there is an addition, that is, adding the information that the original text does not have; finally there is the change of the meaning of the original text. On the other hand, Huang (1991) said in his preface "the translator should keep the integrity of the original work, which is the responsible attitude the translators should have. Any deletion or change of the meaning would diminish the characteristics of the original work". Therefore, it could be imagined that in Huang's translation, he tried to convey all the information to the readers. For example, there are four paragraphs on page forty-seven and forty eight that were not translated, and again four paragraphs without being translated on page thirty-six and thirty-seven of the English original in Fu's translation. As for the partial translation and changed translation, cases exist everywhere.

(10) Scarlett knew these hurried preenings were being made with an eye toward meeting his wife with the appearance of a gentleman who had ridden sedately home from a call on a neighbor. She knew also that he was presenting her with just the opportunity she wanted for opening the conversation without revealing her true purpose. (Mitchell, 2002, p24)

(11) Scarlett could not imagine her mother's hands without her gold thimble or her rustling figure unaccompanied by the small Negro girl whose sole function in life was to remove basting threads and carry the rosewood sewing-box from 
room to room, as Ellen moved about the house superintending the cooking, the cleaning and the wholesale clothesmaking for the plantation. (Mitchell, 2002, p34)

In example ten, Fu did not translate "with the appearance of a gentleman who had ridden sedately home from a call on a neighbor (Mitchell, 2002, p24)" and "without revealing her true purpose", he only translated part of the sentence. And in example eleven, Fu also omitted "rosewood" and "whose sole function in life", at the same time he added "所以 她不能坐定在哪一个地方做针线的”, which was not written in the original text; for the first part of the sentence, he just changed the sentence structure and the meaning of original sentence. In contrast, Huang translated all the information without any change and omission.

From the examples of these five aspects of differences, we can see that generally Fu's translation is domesticated and Huang's translation is foreignized. However, there were still many sentences towards which they just took use of both the domestication and foreignization.

\section{ILlustrations OF THE Two VERSIONS With TOURY’s THEORY OF DTS AND TRANSLATION NORMS}

In accordance with Toury's theory that translation is a norm-governed activity (Toury, 2001), we know that translation norms are not the rules people made, but the objective requirements people have towards the choices of source texts, translation strategy and the acceptability of the target texts in a certain period or a particular society. While translators must be influenced by these objective requirements and would consciously or unconsciously perform some kind of translation behavior. Obviously, there must be different translation norms in different periods, which exert a subtle influence on the translators. Now let's take a look at the requirements set by the translation norms during these two different periods.

\section{A. Fu's Translation}

First, the movie version of the novel Gone with the Wind was released and cheered before Chinese readers knew of it. So before the translation, people already had their ideas, of course, influenced by the film. Anyone who saw the film knew that it was just a love story; and with the two protagonists' outstanding acting, the movie was also believed to be a true adaptation of the novel. However, because of its own characteristics, the film could not contain all the contents of the work, some of which would certainly be abridged, such as, the psychological description, some dialogues, some background materials, all of which were important in the novel, because these contents would show that the novel was not only a love story but also about American history. (Feng, 1998).

Moreover, Fu's translation was started and completed in 1940s, when the literary works and classics of the former Soviet Union are the main sources of translation, such as, Zhu Shenghao translated Shakespeare's work, Meiyi translated How the Steel is Refined, Li Jianwu translated Madame Bovary, etc. All these works were of instruction and artistic quality, and their translation undoubtedly promoted the development of New Vernacular Literature Campaign and enriched people's minds. So when people combine translation's social function with social reality, the so-called useless light literature of the same time would inevitably be impacted. Therefore, the light literature would not be analyzed thoroughly, maybe readers of that time just thought it as the topic of conversation during their free time. 1949 1966: Translation and Publication of American Literature in China, written by Sun Zhili (1995), made a detailed categorization of the translation and publication of American literature during that time, and also proved the abovementioned point of view.

As a result, the above two factors influenced Fu's viewpoint towards Gone with the Wind, and he said in the preface of his version, “... after reading the novel and seeing the movie, I thought although it could not be treated as the classic, it still could not be regarded as lavatorial as the popular novel does-its popularity is quite understandable," "for the redundant description and analysis of psychology which I think are irrelevant to the development of the plot, I just delete them by paragraphs". (Fu, 1979, p1)

Besides, there is the question of language. Not only Chinese is different from English, even the same language in different time period would show different characteristics, because language is in the constant process of evolution, especially when the people who use this language have a tolerant attitude towards the foreign culture. We should notice that the recognition of vernacular Chinese was after the May 4th Movement of 1919. But it was not well developed, so it could not be used adequately, freely and appropriately. Some translators claimed that translators should "create new modern Chinese", like Qu Qiubai (Chen, 1992, p312); while some pointed out that we should enrich vernacular Chinese with the structure and vocabulary of foreign language, like Lu Xun (Chen, 1992, p312). However, it takes time to improve our language with the advantage of a foreign language, which is just one of many ways. Many translators chose to influence and enrich vernacular Chinese through translation, and still many others chose to turn to classical style of writing. For example, famous translators Zhou Zuoren and Fu Lei both said that by translating foreign literature one could learn from classical style of writing (Chen, 1992, p396), and even the language of most of Lu Xun's translated work was mixed with classical style of writing. So we could conclude that at that time the reality of Chinese language urged translators to benefit from Chinese classic style of writing and expressions of foreign language. From Fu's translation, it is obvious to see that he preferred to make good use of advantages of classical Chinese.

Anyway, the requirements of that time, the translation norms, assumed that the translator should fulfill a function specified by the community and has to do so in a way that is considered appropriate in that community. So under the 
influences of such translation norms, Fu employed domestication as his translation strategy, which was also the mainstream of this period, further proven by China's Literary Translation: from Domestication to Foreignization (Sun, 2002).

\section{B. Huang's Translation}

Huang's version was published in the 1990s, so the background was certainly different from that of Fu's. After the reform and opening up, the Chinese people have come into contact with more foreign cultures, and cultural exchanges have become more frequent. More and more translators have pointed out that we should try our best to introduce Chinese culture abroad, and we should also strive to introduce foreign culture into China. As Sun Zhili (2002) said, in the last two decades of the twentieth century, the translation of foreign literature in China was the fourth prosperous period. So many translators started to translate or retranslate many literary works, among which Gone with the Wind attracted much more attention. After about 50 years, Chinese language developed greatly. Just as Huang (1991, p3) put it in the preface to his version: "Since Gone with the wind was introduced into China, there has been only one version of the novel, that is, Fu Donghua's translation." "Language itself develops incessantly, and one version of a literary work could only last for about forty or fifty years. And there are many parts of the translation that are unacceptable, so it is necessary to retranslate." In the preface, Huang mentioned some unacceptable points in Fu's translation, namely, the translation of characters' names and places' name, the deletion and rewriting of the source text, and the false translation.

All in all, just because of these social norms, literature norms and translation norms, translators adopted different ways of translation. The above examples extracted from the first sixteen chapters of the two editions of Gone with the Wind have best illustrated these points perfectly.

\section{Other Aspects of the Two Versions}

There is another concept worth mentioning here, the initial norm, which in translation involves a basic choice between adhering to the norms realized in the source text, reflecting the norms of the source language and culture, and abiding by the norms commonly found in the target culture and language. Adherence to source norms determines a translation's adequacy with respect to the source text; adherence norms originating in the target culture determines its acceptability within that culture (Baker, 2001, p164). Obviously, even the most adequacy-oriented translation involves shifts from the source text; in fact, the occurrence of shifts has long been acknowledged as a true universal of translation (Toury, 2001, p57). So there is no absolute domestication or foreignization.

In addition to the fact that language is determined by the linguistic realities of the times, the translation strategies used by the two translators are the opposite of the main translation methods, that is, in the translation of Fu, some sentences follow the structure of the original sentence and the superficial meaning of the original sentence; In Huang's translation, there are many sentences which are different from the original sentence structure, and these sentences are translated into its connotative meaning. Besides, for literary citations, Fu also made notes for some of them, i.e. in the first sixteen chapters Fu made twenty-four notes, and in Huang's translation, there are fifty-one notes.

Therefore towards any translation, we could not easily say which one is better, because the translation strategies are determined by social norms. Furthermore, translation strategies also would be influenced by the translator's own language proficiency, language habits, translation routines, etc., which again would form a certain kind of society and culture.

\section{CONCLUSION}

Translation is conceived as a norm-governed activity in Toury's theory (Toury, 2001). Norms refer to the translation of general values or ideas shared by a community - as to what is right and wrong, adequate and inadequate-into performance instructions appropriated for and applicable to particular situations, specifying what is prescribed and forbidden as well as what is tolerated and permitted in a certain behavioral dimension (Toury, 2001). From Toury's explanation, we understand that translation norms are not the rules people made, but the objective requirements people have towards the choices of source texts, translation strategy and the acceptability of the target texts in a specific time period or a particular society. While translators must be influenced by these objective requirements and would consciously or unconsciously perform some kind of translation behavior. Obviously, different time periods would definitely have different translation norms, which exert a subtle influence on translators. Therefore, different translator would take different translation strategies adherent to the mainstream of his period of time.

The point is that in order to evaluate the translated text, it is necessary to analyze the translation norms which influence the translator's translation strategies from the historical point of view. Using this theory, we find that there is no absolute domestication or foreignization, and there is no need to decide which version is better. Considering the differences in the translation norms between the two versions, we know that Fu's version is more popular and acceptable in his time, and Huang's version is preferable under contemporary conditions. Either of the versions is a successful product the translator completed in terms of mainstream and translation norms of his time.

Consequently, translators would be affected by some objective requirements, that is, the translation norms people have in selecting translation materials, translation strategies as well as acceptance of the target text, and then translate source text in a certain way. Therefore, controlled by a specific translation norm, translators tend to take a specific 
translation strategy. So, translation norms should be taken into account when evaluating all translated texts besides some set standards.

\section{REFERENCES}

[1] Baker, Mona. (2001). Routledge Encyclopedia of Translation Studies. London and New York: Routledge.

[2] Chen Fukang. (1992). A History of Translation Theory in China. Shanghai: Shanghai Foreign Language Education Press.

[3] Feng Qinghua. (1998). Studying Translation from the Macroscopical Viewpoint of Cultural Communication. Journal of Foreign of Language. 3, 53-57.

[4] Fu Donghua. (1979). Gone with the Wind (upper volume). Hang Zhou: Zhejiang People's Publishing House.

[5] Fu Donghua. (1979). Gone with the Wind (medium volume). Hang Zhou: Zhejiang People's Publishing House.

[6] Fu Donghua. (1979). Gone with the Wind (lower volume). Hang Zhou: Zhejiang People's Publishing House.

[7] Hermans, Theo. (2004). Translation in Systems Descriptive and System-oriented Approaches Explained. Shanghai: Shanghai Foreign Language Education Press.

[8] Huang Huairen \& Zhu Youruo. (1991). Gone with the Wind. Hang Zhou: Zhejiang People's Publishing House.

[9] Mitchell, Margaret. (2002). Gone with the Wind. Beijing: Contemporary China Publishing House.

[10] Sun Zhili. (1995). 1949-1966: Translation and Publication of American Literature in China. Journal of PLA University of Foreign Languages. 4, 71-79.

[11] Sun Zhili. (2002). China's Literary Translation: from Domestication to Foreignization. Chinese Translation. 1, 40-44.

[12] Toury, Gideon. (2001). Descriptive Translation Studies and Beyond. Shanghai: Shanghai Foreign Language Education Press.

[13] Wen Jun (2003). A Functional Critique of Two Chinese Translations of Gone with the win. Chinese Translation. 5, 40-43.

Xunfeng Yin was born in the city of Tai'an, Shandong Province, China in 1976. In March 2006, she earned the degree of M. A. in English in Tianjin Foreign Studies University, China, majoring in the theory and practice of translation. She also is engaged in translation work besides the teaching of English intensive reading, listening and oral class.

As the guide teacher, Ms. Yin won the First Prize of Guide Teacher of the National College Students' English Contest in 2007, 2009 and 2010. 